\title{
Influence of the interposition of ceramic spacers on the degree of conversion and the hardness of resin cements
}

\author{
Patricia Angélica Milani Calgaro \\ Adilson Yoshio Furuse \\ Gisele Maria Correr \\ Bárbara Pick Ornaghi \\ Carla Castiglia Gonzaga
}

Mestrado Profissional em Odontologia Clínica, Universidade Positivo - UP, Curitiba, PR, Brazil.

Declaration of Interests: The authors certify that they have no commercial or associative interest that represents a conflict of interest in connection with the manuscript.

Corresponding Author:

Carla Castiglia Gonzaga

E-mail: carlacgonzaga2@gmail.com

Submitted: Mar 08, 2013

Accepted for publication: Jun 11, 2013

Last revision: Jul 01, 2013
Abstract: This study evaluated: I) the effect of photo-activation through ceramics on the degree of conversion (DC) and on the Knoop hardness (KHN) of light- and dual-cured resin cements; and II) two different protocols for obtaining the spectra of uncured materials, to determine the DC of a dual-cured resin cement. Thin films of cements were photoactivated through ceramics [feldspathic porcelain (FP); lithium disilicate glass-ceramics of low translucency (e.max-LT), medium opacity (e.max$\mathrm{MO}$ ) and high translucency (e.max-HT); glass-infiltrated alumina composite (IC) and polycrystalline zirconia (ZR)] with thicknesses of 1.5 and $2.0 \mathrm{~mm}$. DC was analyzed by Fourier transform infrared (FTIR) spectroscopy. Two protocols were used to obtain the spectra of the uncured materials: I) base and catalyst pastes were mixed, and II) thin films of base and catalyst pastes were obtained separately, and an average was obtained. KHN assessment was performed with cylindrical specimens. The results were analyzed by ANOVA and Tukey's test $(\alpha=0.05)$. The light-cured cement showed higher DC $(61.9 \%)$ than the dual-cured cement $(55.7 \%)$. The DC varied as follows: FP (65.4\%), e.max-HT (65.1\%), e.max-LT (61.8\%), e.max-MO (60.9\%), ZR (54.8\%), and IC (44.9\%). The light-cured cement showed lower KHN (22.0) than the dual-cured (25.6) cement. The cements cured under $1.5 \mathrm{~mm}$ spacers showed higher KHN (26.2) than when polymerized under $2.0 \mathrm{~mm}$ ceramics (21.3). Regarding the two protocols, there were significant differences only in three groups. Thus, both methods can be considered appropriate. The physical and mechanical properties of resin cements may be affected by the thickness and microstructure of the ceramic material interposed during photo-activation.

Descriptors: Resin Cements; Ceramics; Polymerization.

\section{Introduction}

All-ceramic restorations have become popular because of their excellent esthetics, high color stability, wear resistance, and biocompatibility. ${ }^{1,2}$ Even though the mechanical and optical properties of the ceramic materials are important, many variables may contribute to the predictability and clinical longevity of all-ceramic restorations, including the adhesive and luting system used, the curing mechanism, the light-curing unit, and the microstructure and thickness of the ceramic. ${ }^{3}$

Resin cements are necessary to bond porcelain and glass-ceramic resto- 
rations to ensure high strength, ${ }^{4}$ better esthetics and longer clinical survival. ${ }^{5}$ In some situations, lightcured resin cements have been indicated, because of their color stability and longer working time. ${ }^{6}$ However, their maximum degree of conversion (DC) cannot be ensured in situations where light has been attenuated. Therefore, dual-cured luting materials are good options. ${ }^{7}$ However, some studies have demonstrated that they depend on photo-activation to reach high DC and good mechanical properties. ${ }^{8,9}$

The light transmission through a ceramic restoration may affect the degree of polymerization of light- or dual-cured resin cements, because the amount of light that reaches the cement layer is decreased. ${ }^{10}$ In general, the factors affecting light transmission through a ceramic material include the thickness and shade of the ceramic material, its microstructure, and the presence of defects and porosities. $^{11,12}$ Thus, it is important to understand that the performance of light- and dual-cured resin cements will be determined by the amount of light that is transmitted through the restoration and that is able to reach the luting material.

The objectives of this study were:

I. to evaluate the effect of photo-activation through different ceramic spacers of 1.5 and $2.0 \mathrm{~mm}$ thickness on the DC and Knoop hardness number $(\mathrm{KHN})$ of light- and dual-cured resin cements, and

II.to compare two different protocols for obtaining the initial spectra of the uncured materials, to determine the DC of a dual-cured resin cement.

The null hypotheses to be tested were that there would be no difference in the degree of conversion and Knoop hardness between the light- and dualcured cements, regardless of the thickness and type of ceramic during photo-activation, and that there would be no correlation between the values of degree of conversion of the dual-cured resin cement when using two protocols to obtain the initial spectra of uncured materials.

\section{Methodology}

The spacers were fabricated with different ceramics:
- feldspathic porcelain (FP; IPS InLine, IvoclarVivadent, Schaan, Liechtenstein);

- lithium disilicate glass-ceramics (IPS e.max Press, IvoclarVivadent) of low translucency (e.max LT), medium opacity (e.max MO) and high translucency (e.max HT);

- glass-infiltrated alumina composite (IC; In-Ceram Alumina, Vita Zahnfabrick, Bad Säckingen, Germany) and

- polycrystalline zirconia (ZR; Ceramill Zi, Amanngirrbach, Koblach, Austria).

Feldspathic porcelain was prepared in a single layer (1.5- and 2.0-mm-thick). Spacers were prepared for other materials, in two layers of 0.5 or $0.8 \mathrm{~mm}$ thick core material veneered with 1.0 or $1.2 \mathrm{~mm}$ of veneer ceramic. All spacers were fabricated according to the manufacturers' instructions in the corresponding $\mathrm{A} 2$ shade.

Two resin cements were evaluated:

- a light-cured version (RelyX Veneer, 3M ESPE, St. Paul, USA) and

- a dual-cured (Variolink II, IvoclarVivadent) version.

For the purpose of determining the DC, portions of $\approx 0.05 \mathrm{~g}$ of the non-cured cements were dispensed between two plastic films and pressed in a pneumatic press (Simadzu Corp., Kyoto, Japan) at $10 \mathrm{kN}$ to obtain thin films of $\approx 0.1 \mathrm{~mm}$. These films were light-cured for $40 \mathrm{~s}$ through the different ceramic spacers, performed by a LED curing unit (Translux Power Blue, Heraeus Kulzer GmbH, Hanau, Germany), with an irradiance of $1000 \mathrm{~mW} / \mathrm{cm}^{2}$.

Since it is difficult to obtain an accurate spectra of uncured materials for dual-cured resin cements, two different protocols were used for this purpose:

I. base and catalyst pastes were mixed and pressed in order to obtain a thin film, and

II.thin films of base and catalyst pastes were obtained and analyzed separately, and an average of the resulting two spectra was arrived at.

After photo-polymerization, the specimens $(\mathrm{n}=3)^{13,14}$ were submitted to Fourier transform infrared spectroscopy (FTIR 8400, Shimadzu Corp., 
Kyoto, Japan), at $4 \mathrm{~cm}^{-1}$ resolution, and to 32 scans ranging from 4000 to $800 \mathrm{~cm}^{-1}$. The absorption peaks of the aromatic double bonds were recorded at $1608 \mathrm{~cm}^{-1}$ (Abs 1608), and the peak of the aliphatic double bonds were registered at $1636 \mathrm{~cm}^{-1}$ (Abs 1636). The DC of each specimen was estimated as a relative percentage, by using the 2 -frequency method and the tangent baseline technique. The readings were performed immediately for the light-cured resin cement, and after $10 \mathrm{~min}$ for the dual-cured resin cement. This enabled the chemical polymerization of the dual-cured resin cement to attain an advanced stage, as recommended by ISO $4049 .{ }^{15}$

The DC (in percentage terms) was determined as follows:

$D C(\%)=100\left(1-R_{\text {cured }} / R_{\text {non-cured }}\right)$

where $R$ is the ratio between Abs 1636 and Abs 1608 , calculated for both cured and non-cured resin cement.

For the purpose of determining the KHN (kgf/ $\mathrm{mm}^{2}$ ), the specimens were prepared using a Teflon mold (diameter of $10.0 \mathrm{~mm}$ and thickness of $1.0 \mathrm{~mm}$ ) and light-cured through the ceramic spacers for $40 \mathrm{~s}$ (Translux Power Blue). KHN was determined using a microhardness tester (MHT-230, Leco Corp., St Joseph, USA) on the top surface of the specimens (load of $10 \mathrm{~g}$ and dwell time of $10 \mathrm{~s}$ ). Five indentations per sample $(\mathrm{n}=5)$ were performed. The light-cured resin cement specimens were evaluated immediately after curing and the dual-cured resin cement specimens were evaluated 10 min after photo-activation.

Both the DC and the KHN data were submitted to three-way ANOVA and Tukey's test $(\alpha=0.05)$, taking into account the luting cement, the ceramic system, and the ceramic thickness. The two different protocols used to obtain the spectra of the uncured material to evaluate the DC were analyzed using Student's t test $(\alpha=0.05)$.

\section{Results}

Significant differences for DC were observed for the luting cement $(p<0.001)$ and the ceramic sys-
Table 1 - Means and standard deviations for the degree of conversion (in percentage).

\begin{tabular}{|c|c|c|c|}
\hline \multirow{2}{*}{ Thickness } & \multirow{2}{*}{ Ceramic } & \multicolumn{2}{|c|}{ Resin cement } \\
\hline & & Light-cured & Dual-cured \\
\hline- & - & $72.8 \pm 1.5^{a}$ & $67.5 \pm 1.7^{a b c}$ \\
\hline \multirow{6}{*}{$1.5 \mathrm{~mm}$} & FP & $66.9 \pm 4.3^{\mathrm{abc}}$ & $61.0 \pm 2.7^{\text {bcdefgh }}$ \\
\hline & e.max HT & $64.5 \pm 2.2^{\text {bcdef }}$ & $64.8 \pm 3.1^{\text {abcde }}$ \\
\hline & e.max LT & $67.4 \pm 1.1^{\mathrm{abc}}$ & $58.7 \pm 2.2^{\text {defghi }}$ \\
\hline & e.max $M O$ & $67.8 \pm 1.8^{\mathrm{abc}}$ & $55.0 \pm 2.5^{\mathrm{hi}}$ \\
\hline & IC & $54.9 \pm 3.8^{\mathrm{hi}}$ & $42.2 \pm 0.6$ \\
\hline & ZR & $55.5 \pm 2.9^{g h i}$ & $50.8 \pm 3.2^{i}$ \\
\hline \multirow{6}{*}{$2.0 \mathrm{~mm}$} & $\mathrm{FP}$ & $65.4 \pm 3.4^{\mathrm{abcd}}$ & $66.3 \pm 2.8^{\mathrm{ab}}$ \\
\hline & e.max HT & $67.4 \pm 1.8^{\mathrm{abc}}$ & $63.5 \pm 0.4^{\text {bcdefg }}$ \\
\hline & e.max LT & $61.0 \pm 4.3^{\text {bcdefgh }}$ & $60.1 \pm 2.2^{\text {cdefgh }}$ \\
\hline & e. $\max M O$ & $64.1 \pm 1.2^{\text {bcdef }}$ & $56.5 \pm 3.7^{\text {fghi }}$ \\
\hline & IC & $51.3 \pm 1.1^{i}$ & $31.2 \pm 2.4^{k}$ \\
\hline & $Z R$ & $57.1 \pm 0.8^{\text {efghi }}$ & $55.8 \pm 3.8^{g h i}$ \\
\hline
\end{tabular}

Values followed by the same letter are statistically similar $(p>0.05)$.

tem $(p<0.001)$; however, the thickness was not significant $(p=0.322)$. All interactions were significant $(p<0.05)$. The light-cured cement was statistically superior, as compared with the dual-cured cement (61.9\% and $55.7 \%$, respectively). FP $(65.4 \%)$ and e.max HT (65.1\%) spacers showed higher DC for both resin cements. DC results for multiple comparisons are shown in Table 1.

The results for the two different protocols used to obtain the spectra of the uncured materials of the dual-cured resin cement are shown in Table 2. There were statistically significant differences between the DC values only when $2.0 \mathrm{~mm}$-thick FP, IC and ZR spacers were used. There was a positive correlation $(r=0.94)$ between the DC values (Figure 1).

KHN results indicated significant differences for all individual factors $(p<0.001)$. All interactions were significant $(p<0.001)$, except for luting cement $\times$ thickness $(p=0.209)$. Comparing the luting materials, the light-cured cement showed a lower KHN value than the dual-cured cement (22.0 and 25.6, respectively). Light-cured materials under $1.5 \mathrm{~mm}$ ceramics showed higher KHN values than those under $2.0 \mathrm{~mm}$ ceramics (26.2 and 21.3, respectively). Cements cured through e.max HT (27.2), FP (27.1) 
Table 2 - Means and standard deviations for the degree of conversion (in percentage) obtained for the dual-cured resin cement when using two different protocols to obtain the spectra of uncured materials.

\begin{tabular}{c|c|c|c}
\hline \multirow{3}{*}{ Thickness } & \multirow{2}{*}{ Ceramic } & \multicolumn{2}{|c}{ Dual-cured resin cement } \\
\cline { 3 - 4 } & & Protocol I & Protocol II \\
\hline \multirow{7}{*}{$1.5 \mathrm{~mm}$} & - & $67.5 \pm 1.7$ & $65.8 \pm 2.8$ \\
\hline & FP & $61.0 \pm 2.7$ & $60.5 \pm 1.5$ \\
\cline { 2 - 4 } & e.max HT & $64.8 \pm 3.1$ & $63.9 \pm 1.3$ \\
\cline { 2 - 4 } & e.max LT & $58.7 \pm 2.2$ & $57.8 \pm 1.6$ \\
\cline { 2 - 4 } & e.max MO & $55.0 \pm 2.5$ & $57.3 \pm 2.5$ \\
\cline { 2 - 4 } & IC & $42.2 \pm 0.6$ & $43.8 \pm 5.5$ \\
\cline { 2 - 4 } & ZR & $50.8 \pm 3.2$ & $51.3 \pm 2.7$ \\
\hline \multirow{5}{*}{$2.0 \mathrm{~mm}$} & FP & $66.3 \pm 2.8^{*}$ & $58.9 \pm 3.4^{*}$ \\
\cline { 2 - 4 } & e.max HT & $63.5 \pm 0.4$ & $61.8 \pm 1.4$ \\
\cline { 2 - 4 } & e.max LT & $60.1 \pm 2.2$ & $58.1 \pm 2.4$ \\
\cline { 2 - 4 } & e.max MO & $56.5 \pm 3.7$ & $54.7 \pm 1.0$ \\
\cline { 2 - 4 } & IC & $31.2 \pm 2.4^{*}$ & $16.0 \pm 2.7^{*}$ \\
\cline { 2 - 4 } & ZR & $55.8 \pm 3.8^{*}$ & $47.1 \pm 4.10^{*}$ \\
\hline
\end{tabular}

In each line, the asterisks indicate statistically significant differences $(p<0.05)$.

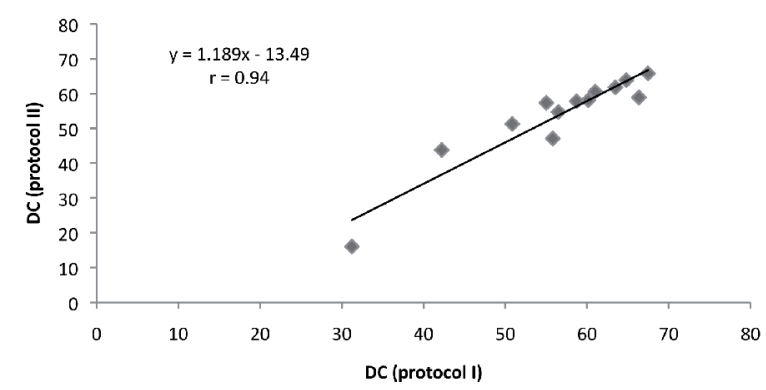

Figure 1 - Correlation between the DC determined when using the two protocols to obtain the uncured material spectra.

and e.max MO (26.4) showed higher values. Multiple comparisons for KHN can be seen in Table 3.

A positive correlation $(\mathrm{r}=0.58)$ was observed between the DC and the KHN (Figure 2). Individual correlation curves are also shown $(\mathrm{r}=0.86$ and $r=0.80$ for light- and dual-cured resin cements, respectively).

\section{Discussion}

The first null hypothesis was rejected. Differ-
Table 3 - Means and standard deviations for the Knoop hardness number (KHN).

\begin{tabular}{|c|c|c|c|}
\hline \multirow{2}{*}{ Thickness } & \multirow{2}{*}{ Ceramic } & \multicolumn{2}{|c|}{ Resin cement } \\
\hline & & Light-cured & Dual-cured \\
\hline- & - & $27.6 \pm 2.3^{\text {def }}$ & $33.6 \pm 2.7^{a}$ \\
\hline \multirow{6}{*}{$1.5 \mathrm{~mm}$} & FP & $27.7 \pm 2.5^{\mathrm{de}}$ & $32.2 \pm 1.8^{a b}$ \\
\hline & e.max HT & $24.5 \pm 4.4^{\mathrm{ghi}}$ & $30.8 \pm 1.8^{b c}$ \\
\hline & e.max LT & $24.4 \pm 3.4^{\text {ghii }}$ & $31.0 \pm 3.2^{\mathrm{abc}}$ \\
\hline & e. $\max M O$ & $29.0 \pm 4.4^{c d}$ & $28.4 \pm 1.8^{\text {cde }}$ \\
\hline & IC & $20.0 \pm 1.8^{\mathrm{kl}}$ & $21.7 \pm 2.6^{i k}$ \\
\hline & ZR & $21.8 \pm 3.0^{i \mathrm{kk}}$ & $23.0 \pm 2.0^{\text {hii }}$ \\
\hline \multirow{6}{*}{$2.0 \mathrm{~mm}$} & FP & $22.4 \pm 1.9^{\text {hijk }}$ & $26.0 \pm 2.0^{\mathrm{efg}}$ \\
\hline & e.max HT & $24.9 \pm 2.4^{\mathrm{fgh}}$ & $28.4 \pm 2.2^{\text {cde }}$ \\
\hline & e.max LT & $19.0 \pm 3.0^{1 \mathrm{~m}}$ & $26.9 \pm 1.5^{\text {defg }}$ \\
\hline & e. $\max M O$ & $21.8 \pm 2.5^{\mathrm{ik} k}$ & $26.6 \pm 2.4^{\text {defg }}$ \\
\hline & IC & $11.7 \pm 1.8^{\circ}$ & $14.2 \pm 2.5^{\text {no }}$ \\
\hline & ZR & $16.6 \pm 2.0^{m n}$ & $17.6 \pm 2.0^{\mathrm{mm}}$ \\
\hline
\end{tabular}

Values followed by the same letter are statistically similar $(p>0.05)$.

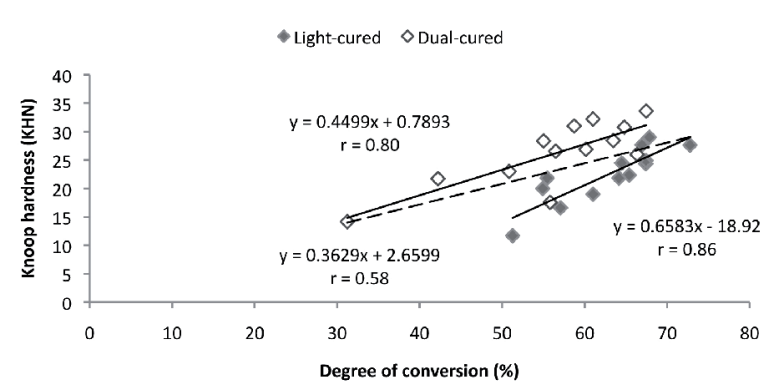

Figure 2 - Correlation between DC and KNH. The solid lines are individual regressions to light- and dual-cured cements. The dashed line indicates the regression for all data points.

ences in the behavior of the two cements may be the result of differences in composition, amount of chemical activator and photo-initiators, and also of the general composition of the cement, including type and proportion of monomers. ${ }^{16}$ Furthermore, DC results may be explained by differences in the reaction rates between the two activation mechanisms. Photo-activation is described as resulting from quick initial curing, whereas chemical activation is characterized by a slower and more progres- 
sive polymerization process. ${ }^{17}$

In the present study, the results indicated that the microstructure of ceramics seemed to influence both the KHN and the DC. IC and ZR spacers accounted for a greater decrease in the KHN and DC values of the two cements, as compared with ceramic spacers with a higher content of glass matrix (porcelain and glass-ceramics). The effect of the ceramic microstructure on the properties of resin cements has also been previously reported in the literature. ${ }^{18}$ The opacity, rather than the thickness, seems to be the main factor accounting for the differences found in DC and KHN among the groups in the present study. However, the thickness of indirect materials interposed during photo-activation is a key factor for light attenuation, and polymerization generally decreases as thickness increases. ${ }^{12}$

Some studies employing FTIR or FT-Raman used thick (from 0.5 to $1.0 \mathrm{~mm}$ ) specimens, ${ }^{14,19}$ approximately 10 to 20 times thicker than those used in the adhesive luting of indirect restorations. Furthermore, there is a difference in the behavior of thin films as opposed to bulk specimens. ${ }^{20}$ In the present study, thin specimens were used to determine the DC, striving to simulate clinical situations of luting indirect restorations adhesively. Thus, the comparison of the results between DC and KHN may have been disparate (low coefficient of correlation), because thin films were used to determine the DC, and thicker specimens were used to determine the KHN.

Some studies have evaluated light-cured resin cements through ceramics. ${ }^{3,18,21,22}$ Overall, they correlated low KHN to low values of DC. However, in addition to the $\mathrm{C}=\mathrm{C}$ conversion, indirect activation through ceramic materials may affect hardness by reducing the intensity of the light reaching the cement, favoring the formation of polymers with a small number of cross-link bonds. ${ }^{23}$ Additionally, other characteristics may also interfere with hardness, including the chemical structure of the monomers and the type and density of the cross-link bonds. ${ }^{24}$ This means that the relation between DC and hardness is not always straightforward. ${ }^{25}$

Although light-cured resin cements are usually indicated for cementation of thin porcelain and glass-ceramic veneers, as well as inlays and onlays, in the present study, this cement was also evaluated under IC and ZR, for the purpose of comparison with the maximum polymerization achieved by curing without any spacer. Thus, a measure of maximum and minimum conversion of resin monomers could be established. By evaluating what the lowest DC would be by employing opaque ceramic spacers, the light attenuation caused by the decrease in the light transmittance through the different ceramics may be better understood.

The second null hypothesis was also rejected. In general, there is not much information on how the initial spectra of uncured materials can be obtained, thereby complicating the reproduction of the test method. This issue is important for dual-cured cements, because their polymerization starts immediately after mixing the base and catalyst pastes, making it difficult to obtain the spectra of uncured materials accurately. Because most studies indicate that the spectra of uncured materials are acquired right after mixing the base and catalyst pastes, it was decided that another protocol would be evaluated, in which thin films with equal amounts (by weight) of base and catalyst pastes would be obtained and analyzed separately, and an average of these two spectra would then be arrived at. In theory, this protocol would avoid obtaining the spectrum of a material already in the initial stages of polymerization. A similar method (with thin films of the individual pastes) has been described in the literature, but there was not much information on how the data was dealt with. ${ }^{26}$ Furthermore, other studies comparing these two protocols were not found.

The present study showed that both protocols may be used, insofar as the majority of the groups showed no significant difference between DC values. The absence of major differences between the two protocols may be accounted for by the fact that self-polymerization of dual-cured resin cements is slower, as compared with self-cured cements. Moreover, the amount of self initiator (normally benzoyl peroxide) needed to induce the reaction in dualcured resin cements is smaller than in self-cured materials. However, in three groups with $2.0 \mathrm{~mm}$ thick spacers, the proposed protocol showed lower DC, as compared to the standard protocol [FP 
$(-11.26 \%)$, ZR $(-15.68 \%)$ and IC $(-48.66 \%)]$. Since there were no other studies to compare and validate these results, more studies are needed so that this alternative protocol may be used as another option to determine the DC of dual-cured resin cements, eliminating the bias of determining the spectra of uncured materials after the polymerization reaction has already started.

The physical and mechanical properties of resin cements may be affected by the thickness and microstructure of ceramic restorations. It is important to emphasize that light-cured resin cements should receive an adequate energy density to reach good polymerization and mechanical properties. Furthermore, only effective photo-activation may ensure

\section{References}

1. Olivera AB, Marques MM. Esthetic restorative materials and opposing enamel wear. Oper Dent. 2008 May-Jun;33(3):332-7.

2. Samra AP, Pereira SK, Delgado LC, Borges CP. Color stability evaluation of aesthetic restorative materials. Braz Oral Res. 2008 Jul-Sep;22(3):205-10.

3. Rasetto FH, Driscoll CF, Prestipino V, Masri R, von Fraunhofer JA. Light transmission through all-ceramic dental materials: a pilot study. J Prosthet Dent. 2004 May;91(5):441-6.

4. Rosenstiel SF, Land MF, Crispin BJ. Dental luting agents: A review of the current literature. J Prosthet Dent. 1998 Sep;80(3):280-301.

5. Malament KA, Socransky SS. Survival of Dicor glass-ceramic dental restorations over 16 years. Part III: effect of luting agent and tooth or tooth-substitute core structure. J Prosthet Dent. 2001 Nov;86(5):511-9.

6. Archegas LR, Freire A, Vieira S, Caldas DB, Souza EM. Colour stability and opacity of resin cements and flowable composites for ceramic veneer luting after accelerated ageing. J Dent. 2011 Nov;39(11):804-10.

7. Santos Jr GC, El-Mowafy O, Rubo JH, Santos MJ. Hardening of dual-cure resin cements and a resin composite restorative cured with QTH and LED curing units. J Can Dent Assoc. 2004 May;70(5):323-8.

8. Braga RR, Cesar PF, Gonzaga CC. Mechanical properties of resin cements with different activation modes. J Oral Rehabil. 2002 Mar;29(3):257-62.

9. Moraes RR, Boscato N, Jardim PS, Schneider LF. Dual and self-curing potential of self-adhesive resin cements as thin films. Oper Dent. 2011 Nov-Dec;36(6):635-42.

10. Heffernan MJ, Aquilino SA, Diaz-Arnold AM, Haselton DR, Stanford CM, Vargas MA. Relative translucency of six clinically acceptable hardness levels of dual-cured resin cements, mainly in critical areas. Considering these issues, further studies are needed to find a way to compensate light attenuation aggravated by the interposition of indirect restorative materials.

\section{Conclusions}

The interposition of ceramic spacers during photo-polymerization significantly influenced the DC and the KHN of the resin cements evaluated. A positive correlation between the DC and KHN values was observed. Regarding the two different protocols used to obtain the uncured spectra of dual-cured resin cements, both methods seem appropriate for determining the DC.

all-ceramic systems. Part I: core materials. J Prosthet Dent. 2002 Jul;88(1):4-9.

11. Lee IB, An W, Chang J, Um CM. Influence of ceramic thickness and curing mode on the polymerization shrinkage kinetics of dual-cured resin cements. Dent Mater. 2008 Aug;24(8):1141-7.

12. Soares CJ, Silva NR, Fonseca RB. Influence of the feldspathic ceramic thickness and shade on the microhardness of dual resin cement. Oper Dent. 2006 May-Jun;31(3):384-9.

13. Papazoglou E, Rahiotis C, Kakaboura A, Loukidis M. Curing efficiency of a photo- and dual-cured resin cement polymerized through 2 ceramics and a resin composite. Int J Prosthodont. 2006 Jan-Feb;19(1):34-6.

14. Papazoglou E, Rahiotis C, Kakaboura A, Loukidis M. Polymerization efficiency of dual-polymerized resin cements light-irradiated through ceramics and laboratory-processed resin composite. Eur J Prosthodont Restor Dent. 2008 Mar;16(1):15-9.

15. International Organization for Standardization. ISO 4049:2009 - Polymer-based filling, restorative and luting materials. 4th ed. Geneva: ISO; 2009. 28 p.

16. Peutzfeldt A. Dual-cure resin cements: in vitro wear and effect of quantity of remaining double bonds, filler volume, and light curing. Acta Odontol Scand. 1995 Feb;53(1):29-34.

17. Fonseca RG, Cruz CA, Adabo GL. The influence of chemical activation on hardness of dual-curing resin cements. Braz Oral Res. 2004 Jul-Sep;18(3):228-32.

18. Borges GA, Agarwal P, Miranzi BA, Platt JA, Valentino TA, Santos PH. Influence of different ceramics on resin cement Knoop Hardness Number. Oper Dent. 2008 NovDec;33(6):622-8. 
19. Franca FA, Oliveira M, Rodrigues JA, Arrais CA. Pre-heated dual-cured resin cements: analysis of the degree of conversion and ultimate tensile strength. Braz Oral Res. 2011 MarApr;25(2):174-9.

20. Moraes RR, Brandt WC, Naves LZ, Correr-Sobrinho L, Piva E. Light- and time-dependent polymerization of dual-cured resin luting agent beneath ceramic. Acta Odontol Scand. 2008 Oct;66(5):257-61.

21. Ilie N, Hickel R. Correlation between ceramics translucency and polymerization efficiency through ceramics. Dent Mater. 2008 Jul;24(7):908-14.

22. Pick B, Gonzaga CC, Steagall Junior W, Kawano Y, Braga $\mathrm{RR}$, Cardoso PE. Influence of curing light attenuation caused by aesthetic indirect restorative materials on resin cement polymerization. Eur J Dent. 2010 Jul;4(3):314-23.

23. Schneider LF, Moraes RR, Cavalcante LM, Sinhoreti MA, Correr-Sobrinho L, Consani S. Cross-link density evaluation through softening tests: effect of ethanol concentration. Dent Mater. 2008 Feb;24(2):199-203.

24. Calheiros FC, Daronch M, Rueggeberg FA, Braga RR. Degree of conversion and mechanical properties of a BisGMA:TEGDMA composite as a function of the applied radiant exposure. J Biomed Mater Res B Appl Biomater. 2008 Feb;84(2):503-9.

25. Furuse AY, Mondelli J, Watts DC. Network structures of BisGMA/TEGDMA resins differ in DC, shrinkage-strain, hardness and optical properties as a function of reducing agent. Dent Mater. 2011 May;27(5):497-506.

26. Noronha Filho JD, Brandao NL, Poskus LT, Guimaraes JG, Silva EM. A critical analysis of the degree of conversion of resin-based luting cements. J Appl Oral Sci. Sep-Oct;18(5):442-6. 